\title{
Integrated and sustainable agroecological production a model of economic and social sustainability for family farmers of the community association
}

\author{
Daniel da Silva Antunes ${ }^{1}$, Cláudio Nahum Alves² \\ ${ }^{1,2}$ Programa de Pós-Graduação em Ciências e Meio Ambiente do Instituto de Ciências Exatas e Naturais da Universidade Federal do Pará \\ (PPGCMA-ICEN-UFPA). Rua Augusto Corrêa, Nº1. Guamá. Belém - PA. CEP: 66075-110. PABX +55 91 $3201-7000$.
}

Email: dantunes.tde@gmail.com,nahum@ufpa.edu.br

Received: Outubro $21^{\text {th }}, 2016$

Accepted: February $23^{\text {th }}, 2017$

Published: March $30^{\text {th }}, 2017$

Copyright (2016 by authors and Institute of Technology Galileo of Amazon (ITEGAM) This work is licensed under the Creative Commons Attribution International License (CC BY 4.0).

http://creativecommons.org/licenses/by/4.0/ cc) (i) (2) Open Aceest

\section{ABSTRACT}

It is known that man, throughout his territorial occupation and for the sake of his survival, was instructed a use of natural resources as an economic and social instrument. As soon as different human actions exert influences on an environmental sustainability, and among these, an agriculture stands out. Following this panorama, the main objective of this article is to elucidate issues that permeate an integrated and sustainable agroecological production: a model of economic and social sustainability for family farmers of the community association Francisco de Assis, located in the municipality of Rio Preto da Eva-AM, focusing activities in the cultivation of vegetables within the principles and practices that guide the farming system focused on agroecology with the theme, Integrated and Sustainable Agroecological Production. The respective study also has as complementary objectives to reveal and to analyze the problems faced by the producers who use agroecological methods of cultivation based on the preservation of the natural resources and conservation of the soil, there is no technical support, foment to the production, sale and commercialization of the products, Aiming With this to contextualize the economic, social and sustainable viability, as an adequate arrangement model for small family farmers. Thus, a qualitative research, where its analysis had as methodological processes the historical, social, economic and environmental procedure in which it is possible to reveal the elements of some theorists that deal with the thematic axis.

Keywords: Agroecology. Sustainability. Environmental impacts

\section{RESUMO}

Produção Agroecológica Integrada e Sustentável: um Modelo de Sustentabilidade Econômica e Social para Agricultores Familiar da Associação da Comunidade

Sabe-se que o homem, ao longo de sua ocupação territorial e em prol de sua sobrevivência, instruiuse a utilizar os recursos naturais como instrumento econômico e social. Logo as diferentes ações humanas exercem influências sobre a sustentabilidade ambiental, e dentre essas, destaca-se a agricultura. Seguindo este panorama, o presente artigo tem como objetivo principal elucidar questões que permeiam a produção agroecológica integrada e sustentável: um modelo de sustentabilidade econômica e social para agricultores familiar da associação da comunidade são Francisco de Assis, localizado no município do rio Preto da Eva-AM, enfocando atividades no cultivo de hortaliças dentro dos princípios e práticas que norteiam o sistema de cultivo voltado para agroecologia com o tema, Produção Agroecológica Integrada e Sustentável. O respectivo estudo também tem como objetivos complementares revelar e analisar os problemas enfrentados pelos produtores que utilizam métodos de cultivo agroecológicos com base na preservação dos recursos naturais existentes e conservação do solo, no tocante a assistência técnica, fomento à produção, escoamento e comercialização dos produtos, visando com isso contextualizar a viabilidade econômica, social e sustentável, enquanto modelo de arranjo produtivo apropriado para pequenos agricultores familiar. Sendo assim a pesquisa é de caráter qualitativa, onde sua análise teve como processos metodológico o procedimento histórico, social econômico e ambiental onde se fez possível revelar os apontamentos de alguns teóricos que tratam sobre o eixo temático.

Palavras-chave: Agroecologia. Sustentabilidade. Impactos Ambientais. 


\section{INTRODUÇÃO}

Sabe-se que o homem em sua história evolutiva em e suas atitudes comportamentais sempre primou e prima por sua sobrevivência e de sua família. Nesse sentido, a prática do cultivo de hortaliças através do sistema chamado de agricultura sustentável, foi exercida no passado antes mesmo do surgimento de novas tecnologias e se tornou peça fundamental de sobrevivência de uma gama de pessoas na atualidade. Diante de tal importância o trabalho dentre suas especificidades tem como objetivo basilar aclarar questões que permeiam a produção agroecológica integrada e sustentável, um modelo de sustentabilidade econômica e social para agricultores familiar da associação da comunidade são Francisco de Assis no Município de Rio Preto da Eva - Amazonas.

Hoje numa ralação de percepção ambiental, homem e natureza, esse método de produção ganha força, não somente pelo aspecto do apelo social quanto à preservação ambiental que visa reduzir ou eliminar danos causados ao meio ambiente, mais também por uma sociedade mais informada que demanda produtos com mais benefícios e nenhum risco a saúde humana.

Vale ressaltar que desde que o homem se tornou parte dominante e muitas vezes dominadas pela natureza, sua tendência se pauta principalmente pela sobrevivência, sendo a atividade agrícola para os pequenos agricultores dessa região, a única lacuna encontrada para obter uma alimentação de boa qualidade, como também, um arranjo produtivo gerador de mão-de-obra e renda as muitas famílias existentes nesse espaço geográfico.

O motivo que levou a realizar o presente estudo configura-se na importância de elucidar o modelo de produção de hortaliças cultivado através do sistema agroecológico do programa PAIS, adotado pelos pequenos agricultores familiar dessa associação na região. Pois através desse conhecimento o estudo proporcionará uma visão realista desse arranjo produtivo, e os indicativos encontrados servirão de estímulo para geração de agricultores futuros, ou até mesmo para outras associações ou cooperativas de produtores rurais em outros municípios da região, como também, para as instituições que elaboram e promovem políticas públicas voltadas para agricultura familiar no Estado do Amazonas.

O referido artigo orientou-se no sentido de coletar dados primários e secundários, que nortearam essa pesquisa. Assim podese afirmar que tal estudo foi capaz de identificar os fatores relevantes no que tange ao desenvolvimento sustentável para com o uso dos recursos naturais no cultivo de hortaliças desde sua inicialização bem como o escoamento e comercialização além dos problemas enfrentados pelos agricultores que utilizam métodos de cultivo agroecológico visando fundamentalmente esclarecer a viabilidade econômica, social e sustentável de integrantes dessa associação.

É importante elencar, e para que haja o entendimento mútuo, o estudo traz à tona todo processo de implantação da unidade, que começa com a construção de galinheiro central, área de pastagem das aves, irrigação e área de produção propriamente dita, como também, entender através dos agricultores os custos logísticos e se existe alguma parceria com as políticas públicas, bem como trazer observar quais os possíveis impactos na relação homem natureza no lócus pesquisado.

Este trabalho está estruturado em quatro momentos, o primeiro apresenta o referencial teórico abordando questões sobre a agricultura familiar; $O$ processo dessa dinâmica, a relevância social que a agricultura tem sobre as famílias, a importância da reforma agrária para a agricultura familiar, impactos ambientais provocados pela produção agrícola industrial, o projeto Pais, a indivisibilidade do homem, a natureza no que tange a Agroecologia, a importância dos pequenos produtores na produção de alimentos; bem como as políticas públicas voltadas para atender os pequenos produtores.

$\mathrm{O}$ segundo momento aborda os materiais e métodos utilizados nesse estudo, desvelando a realidade da pesquisa. $\mathrm{O}$ terceiro momento refere-se à análise e discussão dos resultados, enfocando questões norteadoras necessárias para a promoção de mudanças e comprovação das hipóteses. O quarto momento informa as considerações finais, enfatizando os direcionamentos necessários para a justa medida na busca de entender o quanto a produção agroecológica possibilita benefícios ambientais, sociais e econômicos.

\section{REVISÃO BIBLIOGRÁFICA}

\section{II.1 PERCEPÇÕES SOBRE A AGRICULTURA FAMILIAR}

Sabe-se que a agricultura familiar representa hoje em dia a base social para a maioria dos países em desenvolvimento e constitui a principal forma de subsistência para milhões e pessoas no Brasil, especificamente no amazonas onde essa prática vem sendo desenvolvida desde a ocupação deste território. $\mathrm{Na}$ concepção de [1] a agricultura familiar é um segmento muito importante pela diversidade de produtos oferecidos por este setor, atendendo boa parte das demandas do mercado consumidor interno e externo, como também, pela inexpressiva quantidade de mão-deobra relativa à família empregada no campo.

$\mathrm{O}$ autor supracitado elucida em termos práticos que a agricultura familiar teve e ainda tem grande relevância, apesar do pouco investimento que as políticas públicas têm dado a este segmento. De fato, a relevância histórica e econômica da agricultura familiar não tem a devida atenção desde sua égide, pois é pouco conhecida pela população em geral. Esse esquecimento se deu devido à maior atenção dada, durante boa parte da história do país, ao desenvolvimento tecnológico do setor agropecuário empresarial e de outros setores produtivos da economia [2].

Entende-se que agricultura familiar é um ramo da agricultura que abre portas para as famílias de baixa renda crescer financeiramente. Está voltada para uma abordagem mais familiar onde todos possam estar envolvidos, bem como ter uma vida mais digna e saudável. Particularmente na região amazônica a agricultura está pautada num ramo diversificado de produtos agrícolas cultivados e extrativos, entende-se este como um amplo mercado que abre portas até mesmo para exportação, abrindo margem para uma melhoria na renda familiar, mesmo tendo uma mão de obra reduzida que geralmente é a familiar.

Diante desse contexto [1] salienta que "A chamada Revolução Verde, após a Revolução Industrial, aumentou a produção de alimentos quebrando a teoria que previa uma grande escassez de alimentos para a população, devido à desproporcionalidade entre o crescimento populacional e a produção de alimentos. No entanto, notou-se que, ao passar do tempo, mesmo com produções em larga escala de alimentos, ainda assim havia muita fome no mundo, constatando-se que o problema não estava somente com a quantidade de alimentos produzidos, mas com a má distribuição de renda e tecnologia, desperdício, entre outros fatores".

De acordo com [3] o Ministério do Desenvolvimento Agrário, em dados estatísticos de 2006, declarou que o Brasil possui cerca de 14 milhões de agricultores que produzem em 
empreendimentos familiares. Segundo [4] os quatro milhões de estabelecimentos familiares existentes respondem por cerca de $60 \%$ da produção dos alimentos que chegam à mesa dos brasileiros. Isso demonstra a grande importância da agricultura familiar brasileira, pois a mesma responde $77 \%$ da mão-de-obra atualmente ocupada em atividades agrícolas, enquanto que o agronegócio oferece apenas $23 \%$ das oportunidades de trabalho no campo.

Contudo não podemos deixar de elucidar que tal crescente ocasionou alguns problemas, especificamente ambientais, pois nas últimas décadas, as práticas implementadas no sistema de produção agrícola ocasionaram grandes impactos, sendo que a busca incessante por maior produção e produtividade na agricultura tem causado danos irreparáveis ao meio ambiente.

A exploração ambiental está diretamente ligada ao avanço do complexo desenvolvimento tecnológico, científico e econômico que, muitas vezes, tem alterado de modo irreversível o cenário do planeta e levado a processos degenerativos profundos da natureza [5].

$\mathrm{Na}$ concepção de [1] destaca-se como os processos degenerativos mais profundos ocasionados na natureza; a erosão; perda da fertilidade dos solos; a destruição florestal; dilapidação do patrimônio genético e da biodiversidade; a contaminação dos solos, da água, dos animais silvestres, do homem do campo e dos alimentos.

\section{II.2 OS IMPACTOS CAUSADOS PELA AGRICULTURA INDUSTRIALIZADA}

Precisa-se ter mais cuidado com que se utiliza nos plantios, pois essas substâncias que ao mesmo tempo matam as pragas e ajudam os vegetais a crescer e se desenvolver melhor, também são causadoras de danos severos a nossa saúde, principalmente quando não são tomadas as devidas precauções.

As consequências podem ser desastrosas, causando grande prejuízo e uma má qualidade de vida. Nesse sentido a monocultura torna-se um desperdício de tempo e de terreno, pois, ao invés de se utilizar um único espaço para uma única cultura, pode-se usar esse mesmo espaço para cultivar vários outros tipos de espécies, e com isso cultivar e adubar a terra naturalmente sem utilizar-se de agrotóxicos que com o passar dos tempos causam danos irreparáveis a nossa saúde.

A rotação de cultura é uma prática muito usada para se ter um terreno fértil e bem adubado, e ainda assim, utilizar vários plantios no mesmo terreno. Assim utiliza-se pouco ou quase nada de agrotóxico, ajudando os agricultores a oferecerem um produto mais saudável aos seus clientes.

\section{II.3 A IMPORTÂNCIA DA REFORMA AGRÁRIA PARA A AGRICULTURA FAMILIAR}

A partir da década de 1980, o Estado Brasileiro, obrigado a responder a pressões localizadas e como forma de suavizar os inúmeros conflitos que surgiram referentes à posse da terra, dá início a criação dos Projetos de Assentamentos Rurais, como os conhecemos hoje [6].

Dessa forma, o Brasil sobre pressão mediante os conflitos da posse de terras daquela época, viu-se obrigado a criar projetos onde pudesse assentar pessoas sem terra, onde as mesmas pudessem também trabalhar e assim garantir uma vida mais digna e tranquila.

Nessa perspectiva podem causar consequências que provocam uma instabilidade no processo de vida cotidiana do povo
Esses projetos surgem como uma necessidade histórica, de oportunizar ao homem do campo o acesso à terra de forma ordenada e dentro de preceitos legais estabelecidos pela Reforma Agrária no Brasil. No bioma Amazônico, os projetos de instalação de assentamento rural são mais complexos tendo em vista às necessidades de adaptações as legislações específicas do uso da terra voltado à conservação do meio ambiente [6].

Estes surgem da necessidade a muitos almejada por uma população de desfavorecidos que buscam encontrar no campo a dignidade a muito tempo perdida. Ter direito a um pedaço de chão onde se possa plantar, colher, e viver de forma que não maltrate o meio, mas contribua para sua preservação.

A criação de assentamento rural representa uma vitória de luta mediante as reivindicações pela terra, representa também, a possibilidade de melhoria das condições de vida, já que a partir do trabalho com a terra o pequeno produtor pode retirar o seu sustento e até viabilizar-se economicamente através do excedente produzido em sua propriedade [6].

Depois dessa grande conquista sob grandes reivindicações pela terra, surgem ao longe à previsão de melhores dias onde a conquista da terra pode ser vista como meio pelo qual uma grande parcela de marginalizados pudesse tirar seu sustento a garantir uma melhoria financeira através do excedente produzido em seu plantio.

É notório que todo esforço feito durante esses anos até chegarem a conquista da criação de programas dessa natureza que com tanto esforço fora conquistado, como é o caso do assentamento rural é o reconhecimento das lutas diárias vividas por todos esses assentados rurais. Desse modo, graças a essas conquistas o resgate da autoestima desses produtores voltou e hoje é notório que estes cidadãos sentem parte do meio em que estão inseridos, conservando assim, toda sua cultura rural, seus hábitos e costumes os quais são essenciais para manter sua identidade para sempre preservada.

\section{II.4 A IMPORTÂNCIA DOS PEQUENOS PRODUTORES NA PRODUÇÃO DE ALIMENTOS.}

No Brasil, o Programa Nacional de Fortalecimento da Agricultura Familiar dentre os programas governamentais visa "o apoio ao pequeno produtor rural que tinham como objetivo promover o desenvolvimento rural em regiões de baixa renda. Já em 2009 foi lançado o Pronaf Sustentável que, ao focar o financiamento na propriedade rural em sua totalidade, permite o desenvolvimento econômico dos agricultores familiares em paralelo ao desenvolvimento ecológico sustentável"

De acordo com [7], os produtos orgânicos vêm alcançando cada vez mais destaque nos mercados nacional e internacional, devido não somente à mercadoria em si, mas a tudo que a ela está associado; como a responsabilidade com o ambiente, a valorização do trabalhador, a segurança alimentar e a qualidade de vida tanto do produtor quanto do consumidor. Assim, percebese que o número de pessoas dispostas a consumir produtos resultantes de processos menos impactantes à natureza e que sejam provenientes de relações mais justas de produção e de comercialização tem aumentado. Destarte que os fenômenos naturais são componentes que agem direta e indiretamente na plantação desses indivíduos e por muitas vezes determinando tempo e escala de produção agrícola.

afetado e implica na produção social e cultural das pessoas que precisam desses produtos para sobreviver. 
Segundo [8], a tendência de crescimento desse segmento de mercado é devido ao maior fluxo de informações, tornando o consumidor mais consciente sobre a preservação e conservação da natureza. Porém, o comportamento de consumo é complexo e contraditório, que depende do contexto social e cultural dos consumidores. Dando ênfase nesta questão [3] diz que a agricultura familiar brasileira se configura como uma importante atividade agrícola, que aquece o mercado interno, gera emprego e renda a milhares de brasileiros, porém as desigualdades regionais e a falta de incentivo ao fortalecimento à agricultura familiar apresentam-se ainda como entraves ao desenvolvimento agrícola brasileiro.

\section{II.5 POLÍTICAS PÚBLICAS VOLTADAS AOS PEQUENOS PRODUTORES: IMPORTÂNCIA DO (PAA) PARA AGRICULTURA FAMILIAR}

O Programa de Aquisição de Alimentos (PAA) é "uma ação criada pelo governo federal que visa atender o maior número de agricultores possíveis, facilitando seu acesso aos mercados consumidores, melhorias na sua renda, qualidade de vida e facilidade na compra dos alimentos-produtos. Tudo isso sem que estes produtores rurais oriundos da agricultura familiar não tenham a necessidade de enfrentar os processos licitatórios; este programa também destina esses produtos de forma gratuita às pessoas em situação de insegurança alimentar" [9].

Instituído pelo artigo 19 da Lei no 10.696 , de 2 de julho de 2003 e regulamentado pelo Decreto $n^{\circ} 7.775$, de 4 de julho de 2012, o PAA integra o Sistema Nacional de as Segurança Alimentar e Nutricional - SISAN e tem como finalidades principais a promoção do acesso à alimentação e o incentivo da agricultura familiar. $\mathrm{O}$ apoio aos agricultores familiares opera-se por meio da aquisição de produtos da sua produção, com dispensa de licitação [9].

A partir de dois de julho de 2003 passou a ser regulamentado o programa de aquisição de alimentos que propiciou aos agricultores familiares a facilidade de escoarem seus excedentes através vendas sem necessidade de licitação, facilitando a vida do pequeno agricultor e propiciando aos mesmos mais qualidade de vida e menos desperdício de sua produção. As principais metas desse programa são a sustentação de preços ao agricultor, maior geração em sua renda familiar, o fortalecimento do cooperativismo e também uma maior qualidade na sua alimentação.

Nessa perspectiva nota-se um avanço para esses produtores rurais. Com a criação da Lei no 11.947 de 16 de junho de 2009 fica determinado que no mínimo 30\% do valor repassado a estados, municípios e Distrito Federal pelo Fundo Nacional de Desenvolvimento da Educação (FNDE) para o PNAE deve ser utilizado de forma obrigatória na compra de produtos provenientes da agricultura familiar, sem o procedimento de licitação [10].

O Programa também valoriza a produção e a cultura alimentar das populações, dinamizando a economia local, a formação de estoques estratégicos, a melhoria da qualidade dos produtos da agricultura familiar, o incentivo ao manejo agroecológico dos sistemas produtivos e o resgate e preservação da biodiversidade. De acordo com dados publicados pela Gerência de Acompanhamento e Controle das Ações da Agricultura Familiar GECAF, da Companhia Nacional de Abastecimento - CONAB, ressalta que desde a criação do Programa PAA no período de 2003 a 2012, já foram investidos recursos da ordem de 2,7 bilhões de reais. Sendo que somente em 2012, o valor aplicado atingiu o montante de R $\$ 586$ milhões em aquisições, um incremento de $723 \%$ em relação ao ano de 2003. CONAB-GECAF (2009-2013) [11].

\section{MATERIAIS E MÉTODOS III.1 ÁREA DE ESTUDO}

O Município de Rio Preto da Eva aqui pesquisado, além de ser reconhecido pela sua atuação na produção agrícola no

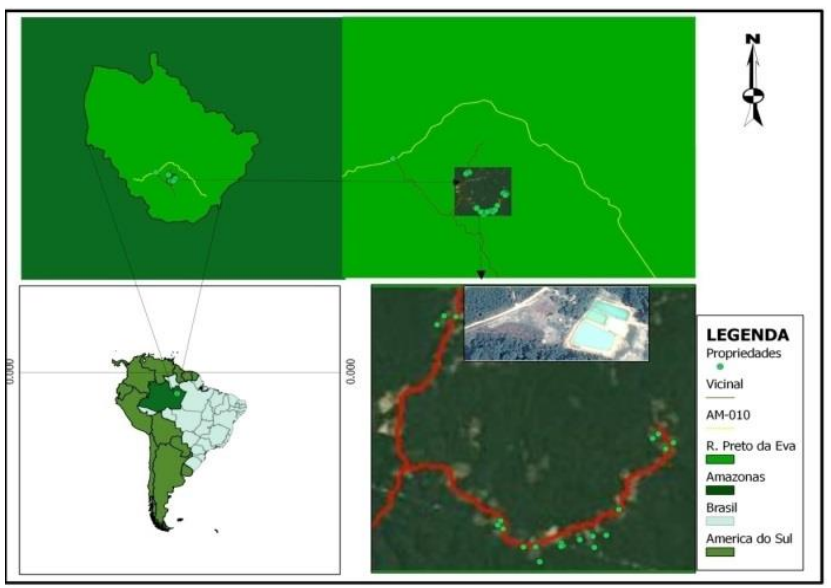

Figura 1: Localização Geográfica Município do Rio Preto da Eva.

Fonte: Autores, (2016).

Seu nome fora criado em consequência das águas pretas (ou escuras) do rio que banha o município. A sede do município está localizada na mesorregião centro amazonense, na $7^{\circ}$ sub- interior do amazonas, se tornou um dos pontos turísticos mais visitados e conhecidos do nosso estado.

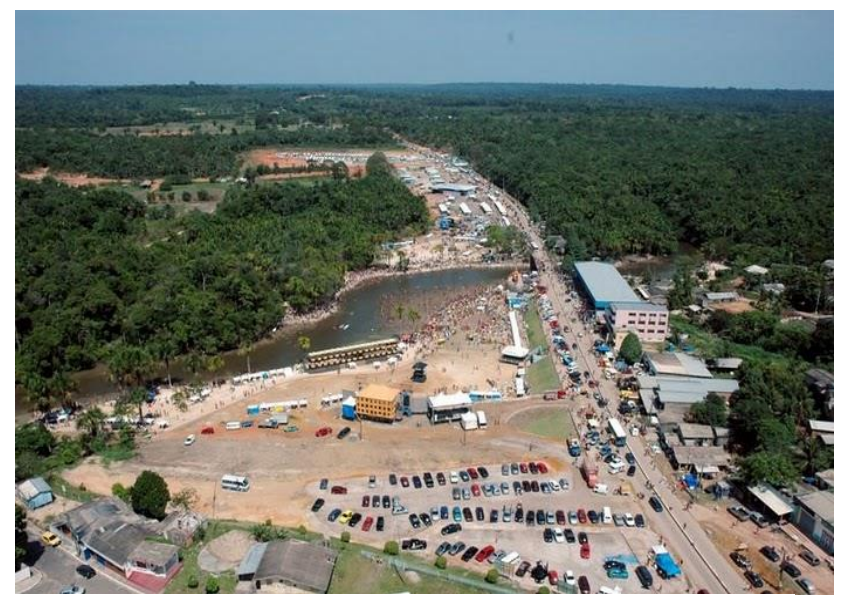

Figura 2: Município de Rio Preto da Eva.

Fonte: Autores. (2016).

região do Rio Negro e Solimões, entre a latitude: 2,69944 S e longitude: 59,69972W. Segundo dados do [12], atualmente Rio Preto da Eva ocupa uma área total de $5.813 \mathrm{~km}^{2}$ e uma população de 26.847 mil habitantes. 


\section{III.2 ASSOCIAÇÃO DA COMUNIDADE SÃO FRANCISCO DE ASSIS - OBJETO DE ESTUDO}

A associação de São Francisco de Assis aqui pesquisada, foi fundada no dia 18 de abril de 2010 com a participação de algumas famílias de agricultores. Atualmente a associação é composta por 78 famílias todos produtores rurais da agricultura familiar, que é presidida pela Senhora Etelvina Mota da Silva. O endereço e sede da associação encontra-se no Ramal da Cachoeira, quilometro 06 - Municípios de Rio Preto da Eva, aproximadamente $80 \mathrm{~km}$ de distância da capital, via AM - 010. É importante salientar que na observação, participante buscou-se coletar dados no envolvimento e interação existentes entre os diferentes atores sociais, fazendo uso neste estudo da pesquisa participante. Para [13] "declara a técnica de observação participante se realiza através do contato direto do pesquisador com o fenômeno observado para obter informações sobre a realidade dos atores sociais em seus próprios contextos".

\section{III.3 MÉTODOS DA PESQUISA}

As técnicas utilizadas foram através de observação participante, um levantamento bibliográfico e Documental, entrevistas aplicadas aos agricultores, análise feita de forma qualitativa, onde foi possível a coleta de relatórios fotográficos e aplicação de questionários.

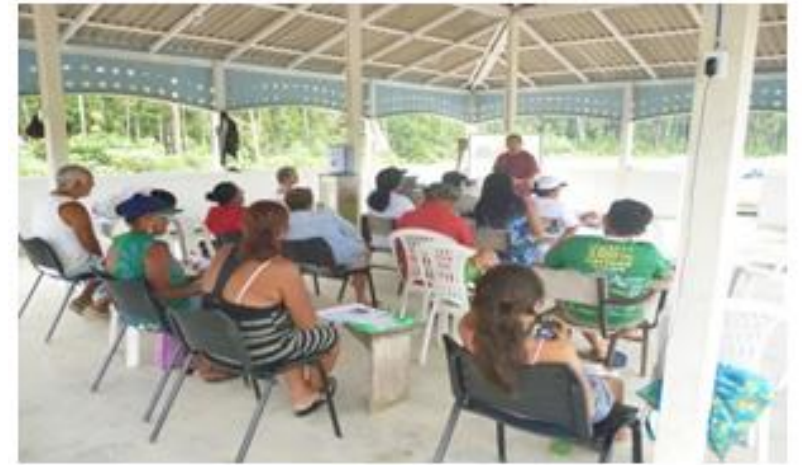

Fig. 1. Aplicação do questionário e pré-palestra sobre Agroecologia e meio ambiente com os agricultores. Fonte: [14].

As Figuras 5, 6 e 7 mostra dentro do setor agrícola e atividades desenvolvidas na região, o setor primário é o mais representativo economicamente. A produção agrícola é baseada no cultivo de produtos cítricos, mandioca para fabricação de farinha,

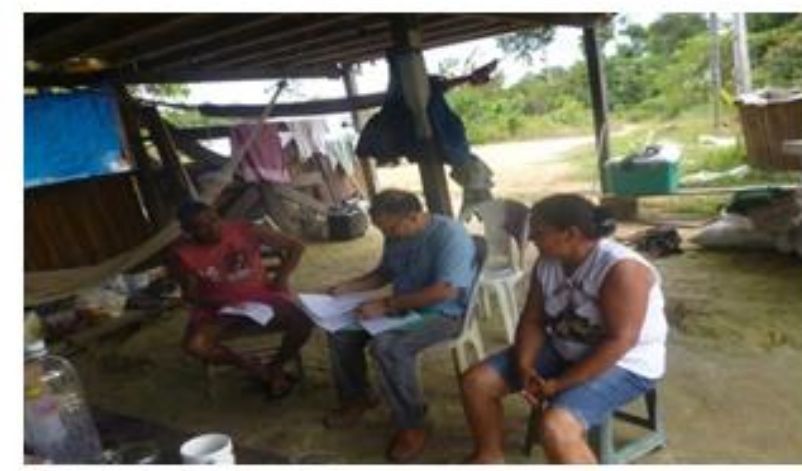

Fig. 4. Aplicação do questionário Fonte: [14].

seguidas da produção de hortaliças, banana, abacaxi, mamão, maracujá, cupuaçu, pupunha, cacau e coco. Mas é na aquicultura que o município está se destacando pelo desenvolvimento em grande escala comercial [15].

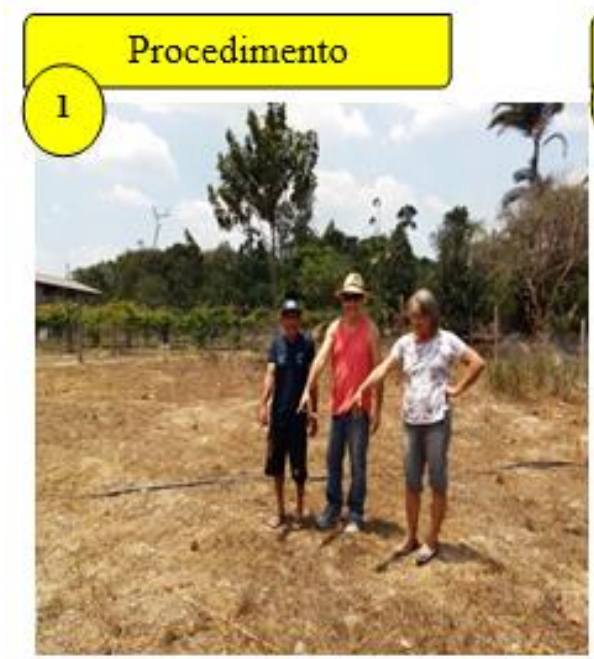

Fig. 5. Escolha da àrea de instalação Fonte: [14].

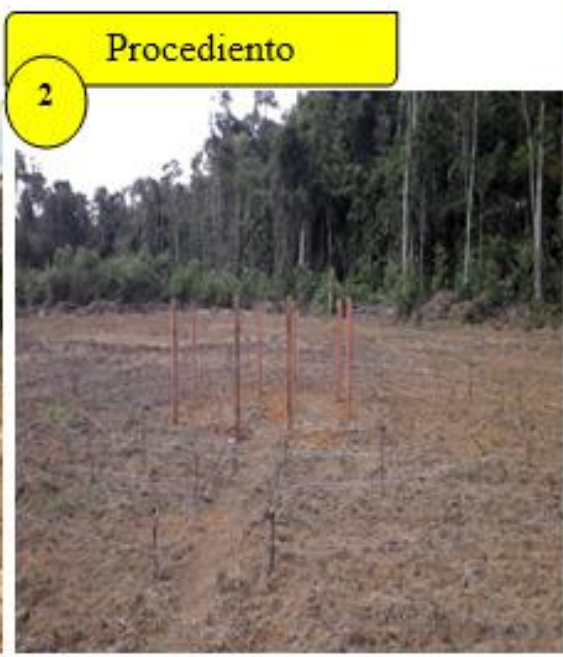

Fig. 6. Demarcação da unidade PAIS Fonte: [14].

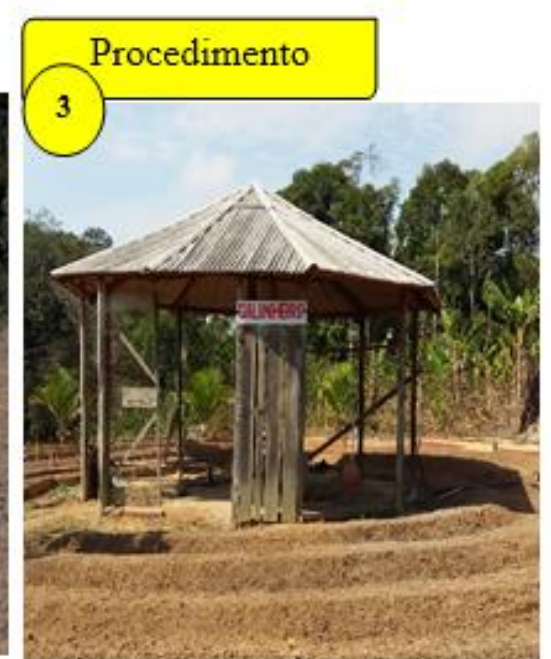

Fig. 7. Construção do Galinheiro Fonte: [14].
A agricultura nessa região é pautada por uma porção de dinâmicas, especificamente na produção de hortaliças. Contudo os diferentes cultivos realizados no Município de Rio Preto da Eva são feitos pelos agricultores que residem e estão diretamente relacionados com o processo de necessidade. O regime do trecho dos plantios é considerado propício para a organização dos inúmeros cultivos, pois à elevação da sua cota de produção se dá com retorno muito rápido. Nesse segmento [16] diz que a 
agricultura familiar, além da diversificação da produção, ao contrário da agricultura convencional, busca equilibrar o uso dos recursos naturais atuando ativamente no processo de transição para uma agricultura sustentável. Vale salientar que os agricultores, já estabelecidos nessa associação, não exercem exclusivamente uma atividade, mas uma combinação de atividades. Essa prática diversificada possibilitou aos agricultores uma maior flexibilidade na produção das hortaliças conforme mostra as figuras 8, 9 e 10.

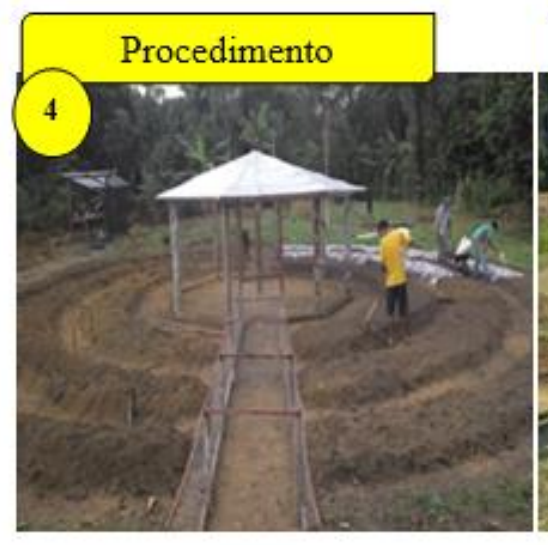

Fig. 8. Preparo das leiras e adubação Fonte: [14].

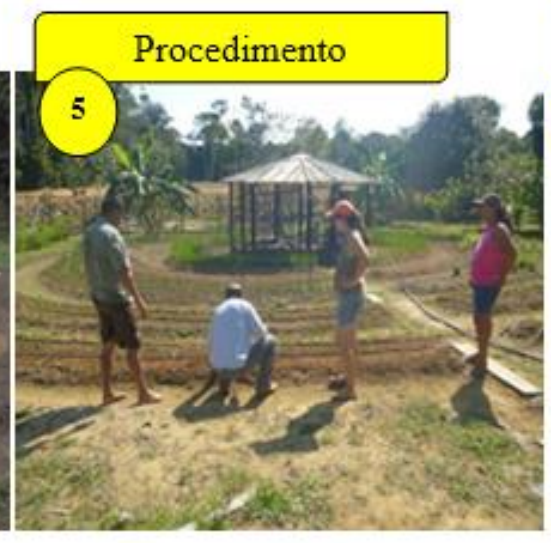

Fig. 9. Irrigação por gotejamento Fonte: [14].

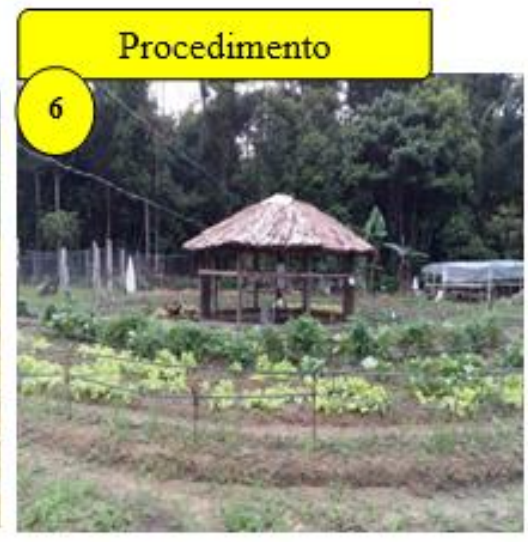

Fig. 10. Hortaliças prontas para colheita Fonte: [14].
As imagens acima demonstram algumas das etapas de preparo das leiras, adubação, irrigação, tratos culturais e colheitas das respectivas hortaliças na Comunidade são Francisco de Assis. É importante salientar que os agricultores fazem parte de um conjunto associativo bem consolidado e com participação efetivas em atividades voltadas para agroecologia em vários eventos promovidos pelo [17][18][26][11] e outras instituições que podem possibilitar maior abertura de locais de comercialização de seus produtos, além da feira já realizada todos os sábados no Município de Rio Preto da Eva. No entanto, para que estes produtos cheguem até a mesa do consumidor com qualidade é necessário que os agricultores sigam sistematicamente algumas leis e regulamentos vigentes, controlados pelo Ministério da Agricultura Pecuária e Abastecimento [19].

Atualmente esta associação conta com a participação de 78 associados, todos agricultores familiar. Importante ressaltar que nos últimos anos a comunidade foi contemplada com 20 (vinte) projetos de agroecologia PAIS sustentável. Sendo que, em ato recente à Associação dos Agricultores da Comunidade São Francisco de Assis (AACSFA) [14] recebeu da Superintendência Federal de Agricultura no Amazonas (SFA/MAPA), o Título de Organização de Controle Social (OCS), e dos 20 projetos do PAIS instalados nas propriedades, 19 receberam a Declaração de Produtor Orgânico vinculado a OCS, por atenderem todos os requisitos estabelecidos como recomenda o orgão.

De acordo com LEI No 10.831, DE 23 DE DEZEMBRO DE 2003 em seu Art. 1 ${ }^{\circ}$ : Considera-se sistema orgânico de produção agropecuária todo aquele em que se adotam técnicas específicas, mediante a otimização do uso dos recursos naturais e socioeconômicos disponíveis e o respeito à integridade cultural das comunidades rurais, tendo por objetivo à sustentabilidade econômica e ecológica, a maximização dos benefícios sociais, a minimização da dependência de energia não renovável, empregando, sempre que possível, métodos culturais, biológicos e mecânicos, em contraposição ao uso de materiais sintéticos, a eliminação do uso de organismos geneticamente modificados e radiações ionizantes, em qualquer fase do processo de produção, processamento, armazenamento, distribuição e comercialização, e a proteção do meio ambiente [20].

Contudo, é imprescindível elencar a percepção dos agricultores dessa região, especificamente sobre a produção de hortaliças agroecológica [21]. Nesse contexto foram direcionadas algumas questões aos respectivos agricultores conforme as Figuras 11 e 12 .

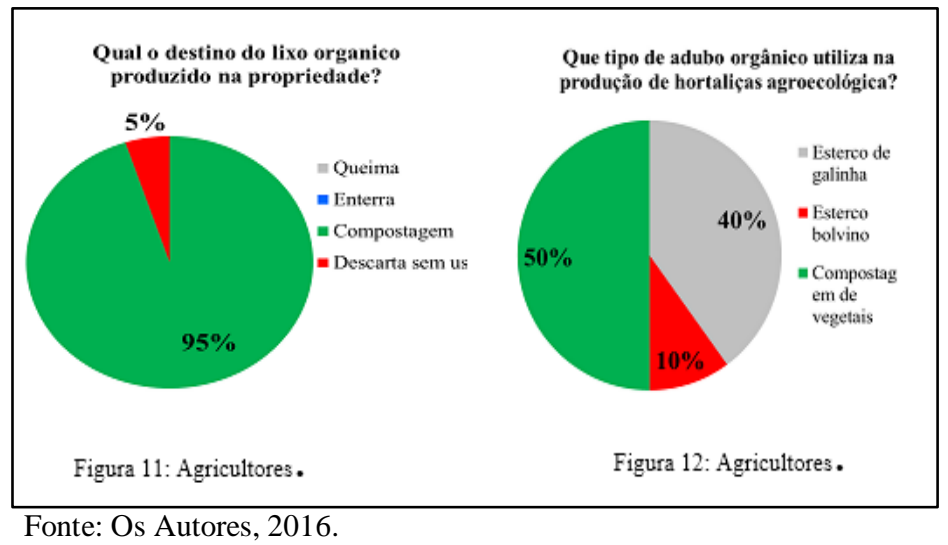

sobre o lixo orgânico produzido na propriedade, é perceptível no sustentáveis, uma vez que $95 \%$ deles afirmam destinar o lixo gráfico (1), que os agricultores dessa associação utilizam métodos 
do mesmo, esses possivelmente utilizam apenas esterco de animais como adubo orgânico na sua produção.

Cerca de um terço dos resíduos produzidos em casa são classificados como resíduos orgânicos. Eles podem ser facilmente transformados em compostos reutilizáveis como adubação de alta qualidade [22]. Os resíduos orgânicos são biodegradáveis, para tanto, foram direcionadas uma pergunta sobre qual tipo de adubo é ultizado na plantação de hortaliças [23]. No gráfico da figura 12, $50 \%$ dos entrevistados elucidam que ultilizam compostagem vegetal para produção de hortaliças, já $40 \%$ informam que a forma de adubação é feita com esterco de galinha, e somente 10\% afirmam usar estercos bovinos [24].

De acordo com o Ministério da Agricultura o produtor orgânico deve fazer parte do Cadastro Nacional de Produtores Orgânicos, o que é possível somente se estiver certificado por um dos três mecanismos descritos a seguir [25]:

a) Certificação por Auditoria - A concessão do selo SisOrg é feita por uma certificadora pública ou privada credenciada no Ministério da Agricultura.

b) Sistema Participativo de Garantia. Caracteriza-se pela responsabilidade coletiva dos membros do sistema que podem

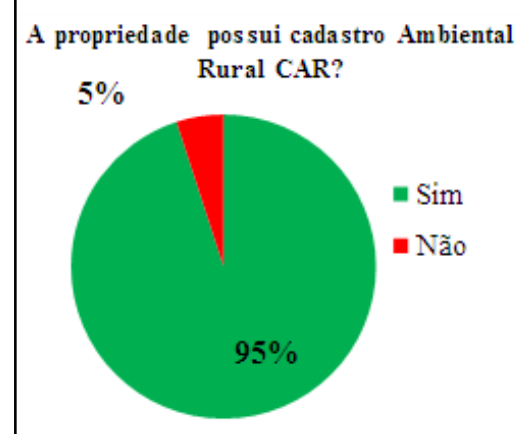

Figura 13: Agricultores.

Fonte: Os Autores, 2016

Independentemente do tamanho de suas atividades existem várias questões jurídicas que você precisa manter em mente quando escolhe seguir o caminho da agricultura, principalmente a produção de hortaliças orgânicas, uma vez que se trata de vegetais frescos e importantes para a saúde e bem-estar do consumidor e do meio ambiente.

Diante de tal fato, o gráfico da figura 13 elucida que $95 \%$ dos agricutores possuem cadastro ambiental rural, e apenas 5\% ainda não possuem, mais segundo eles, já deram entrada no orgão responsável para obtenção. Contudo, percebe-se que a maioria desses profissionais têm se mantido vigilante quanto à importância da legalização do cadastro ambiental rural.

Com o advento da globalização, devido à constante quebra de barreiras comerciais e de produção, a produção agrícola

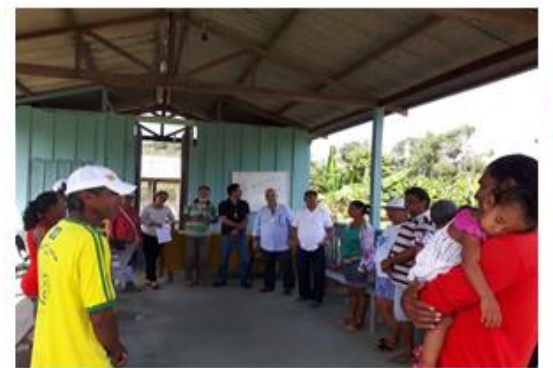

Fig.15. Produtores recebem a Declaração de produtor orgânico vinculado a OCS Fonte: [14]. ser produtores, consumidores, técnicos e demais interessados. Para está legal, um SPG tem que possuir um Organismo Participativo de Avaliação da Conformidade (OPAC) legalmente constituído, que responderá pela emissão do SisOrg.

c) Controle Social na Venda Direta. A legislação brasileira abriu uma exceção na obrigatoriedade de certificação dos produtos orgânicos para a agricultura familiar. Exige-se, porém, o credenciamento numa organização de controle social cadastrado em órgão fiscalizador oficial.

É fato que muitos agricutores nessa região têm a perspectiva de aumentar sua produção e automaticamnte seu poder econômico, mas as hortas que fazem uso eficiente do espaço crescente são; muito mais fáceis de cuidar; se você está falando sobre alguns recipientes no pátio ou um lote de 50 por 100 uma vez que espaços assim não requer tanta burocracia, porém, assim como qualquer outro investinento é nescessario investmentos maiores bem como seguir algumas ações legais. Levando em consideração a vertente apontada foram direcionadas perguntas aos agricultores conforme as Figuras 13 e 14.

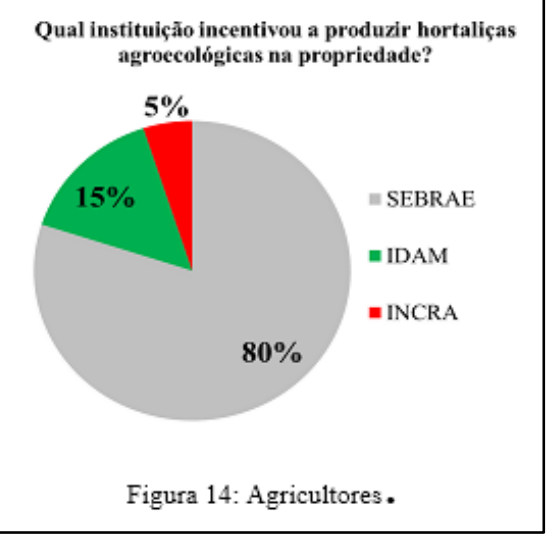

tem tomado proporções exacerbadas, exigindo na busca incessante da excelência e da qualidade dos produtos e serviços para atender ao consumidor de forma mais satisfatória. Levando em consideração tais mudanças é necessário que os agricultores busquem parcerias a fim de melhorar e supostamente aumentar sua produção.

O gráfico da figura 14 viabilizou de forma breve os órgãos que outrora tem atuado nessa parceria com a Associação São Francisco de Assis. Os respectivos agricultores afirmam que $85 \%$ das parcerias provem do SEBRAE Amazonas, e 15\% apresentam-se do IDAM, e apenas 5\% dessa parceria vêm do Instituto Nacional de Colonização e Reforma Agrária (INCRA).

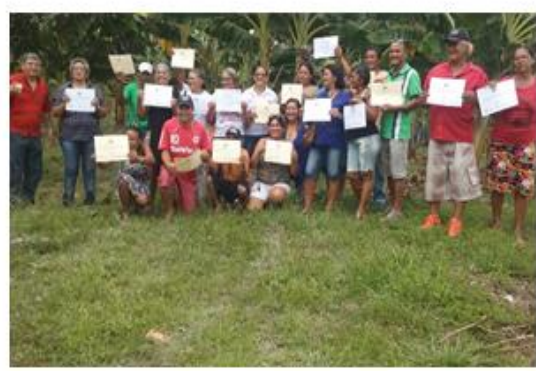

Fig. 16. Reunião na sede da Associação com Equipe técnica do SEBRAE, CONAB, IDAM Fonte: [14]. 
É reconhecido que o desenvolvimento agrícola alimenta o crescimento econômico e é crucial para o alívio e segurança alimentar de muita região, no entanto, apesar de haver parcerias importantes de instituições nesse contexto, existem vários outros fatores que estão associados ao fraco desempenho da agricultura nos últimos anos. Dentre estas conjunturas incluem restrições estruturais e tecnológicas, escoamento da produção e principalmente a falta de políticas públicas mais eficazes a produção agroecológica nessa região. Dando segmento a esta vertente foram direcionadas questões aos agricultores inerentes a parcerias e suas dificuldades em relação à produção e comercilaização das hortaliças conforme mostra as figuras 15 e 16 .

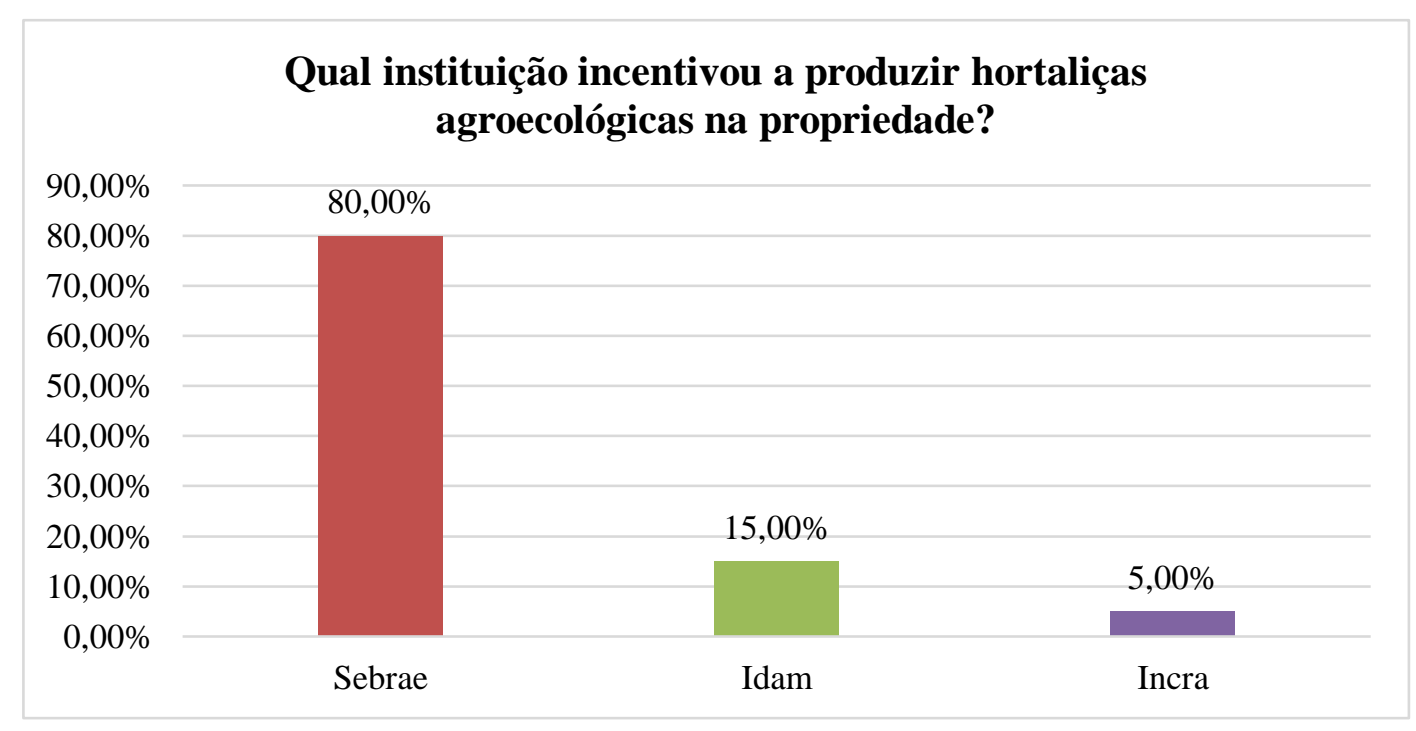

Figura 17: Pergunta direcionada aos Agricultores •

Para estabelecer um regime de seguro agrícola saudável e sustentável baseado em políticas mais abrangentes, uma discussão sobre a importância dessas parcerias é oportuna à luz dos desafios que os governos enfrentam no contexto de escala e frequência de grandes desastres naturais relacionados com a agricultura em todos os aspectos. Contudo, além da oportunidade de melhorar essas relações entre homem e natureza as respectivas parcerias podem servir como eixo motivador para que futuros produtrores possam expandir seu negócio e automaticamente ajudar na economia local através da produção agrícola com uso de práticas conservacionistas.
Considerando tal importância perguntou-se quais as instituições têm motivado a produção de hortaliças nesta associação. O gráfico da figura 17 mais uma vez tem elucidado a grande importância do SEBRAE nessa questão, uma vez que $80 \%$ dos entrevistados afirmam que esta instituição tem motivado para que eles continuem na produção de hortaliças através do programa PAIS.

Com a pesquisa também foi possível revelar as principais dificuldades que os agricultores têm em relação à produção de hortaliças agroecológicas0. Observem o gráfico da figura 18.

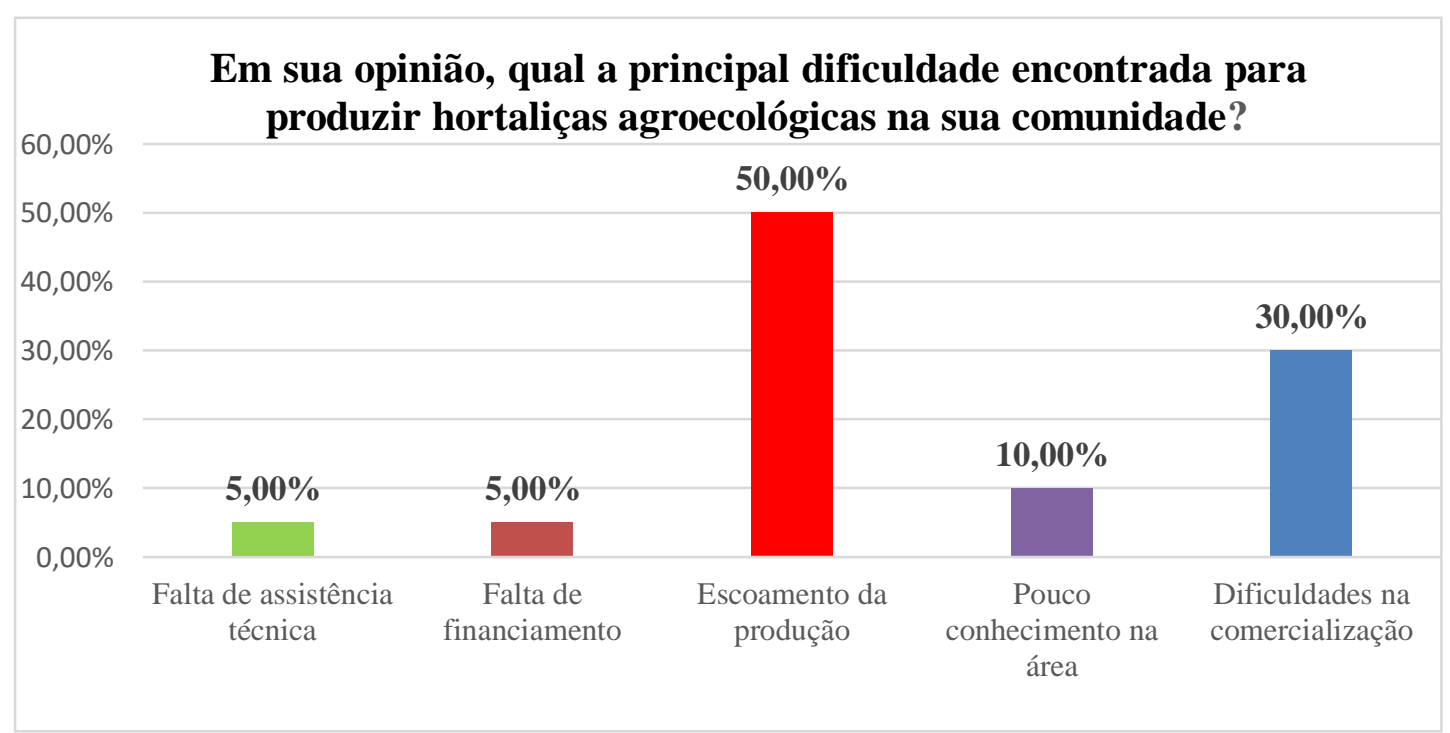

Figura 18: Pergunta direcionada aos Agricultores• 
Como podemos ver no gráfico acima são várias as dificuldades que os agricultores têm na produção de hortaliças. É evidente que a maioria dos agricultores que conseguem se estabelecer como produtores encontram dificuldades para escoar seus produtos, principalmente quando os mesmos têm que se deslocar do local de produção para feira na sede do município, a fim de comercializar seus produtos. Dentre as opções no gráfico $50 \%$ dos agricultores afirmam que a maior problemática existente é justamente o escoamento da produção. E 30\% dos entrevistados elucidam que as dificuldades estão na comercialização.

De acordo com as respectivas dificuldades podemos citar: falta de incentivo ou pelo baixo incentivo dos governantes dessa cidade e do estado, e também pelos castigos da natureza e variações do mercado, bem como a falta de assistência técnica.

É importante salientar que o Ministério da Agriculrura informa que a as Comissões de Produção Orgânica (CPOrg) se reúne regularmente e têm várias atribuições definidas na Instrução Normativa $n^{\circ} 13$, de 28 de maio de 2015, como, por exemplo, coordenar ações e projetos de fomento à produção orgânica; sugerir adequação das normas de produção e controle da qualidade orgânica; auxiliar na fiscalização, pelo controle social; e propor políticas públicas para desenvolvimento da produção orgânica. Sendo que tal atividade é representada por um modo de vida permanente ainda da atividade tradicional que, no entanto, já possui certo grau de evolução tanto na utilização de motores mais potentes como no desenvolvimento de técnica de corte de árvores, e até mesmo de roçado.

Compreender essa produção passa pelo entendimento de que é a família e as relações familiares, bem como a fiscalização e contribuição do estado é de práxis importantíssima, pois são fundamentais para o desenvolvimento e compreensão da realidade amazônica estabelecidas nesses ambientes e neste tipo de atividade.

\section{CONCLUSÃO}

É indispensável, portanto, aos indivíduos, o despertar de uma compreensão e sensibilização em relação à produção de hortaliças nessa região, principalmente por se tratar de assuntos relevantes e inerentes a uma produção sustentável que respeita as biodiversidades e agrossistemas Amazônicos.

Com a implantação de 66 unidades do programa PAIS, em comunidades dos municípios de Presidente Figueiredo, Manaus Entorno e Rio Preto da Eva, iniciadas em 2013, pelo SEBRAE Amazonas em parceria com a Fundação Banco do Brasil e o INCRA, o projeto passou a ter conotação e relevância histórica por ajudar a impulsionar substancialmente a produção de hortaliças agroecológica no estado. Dentro deste contexto abordado no artigo, destaca-se a comunidade de São Francisco de Assis, escolhida como área de estudo que compreende 20 unidades produtivas do programa PAIS, na qual 19 delas já receberam a Declaração de produtor orgânico vinculado a OCS. Desse total, o programa também incentivou na transição da produção de frutíferas do sistema convencional para o orgânico em 9 propriedades da área estudada e, através dos resultados positivos obtidos nessas propriedades, vem incentivando outros produtores a adotarem a mesma prática de cultivo em outras localidades da região.

Nessa perspectiva, o programa também contribui sistematicamente com a geração de renda para as famílias de agricultores beneficiadas, que além de produzir alimentos de boa qualidade para o consumo, auferem lucros com o excedente da produção ajudando a manter o sustento da familiar.
Pode-se observar a relevância desta pesquisa, uma vez que no contexto social, o arranjo produtivo também se destaca pela sua composição, tendo em vista que são formados por agricultores familiar de baixa renda, focados na sustentabilidade $\mathrm{e}$ fundamentalmente bem organizados. Outra questão importantíssima que deve ser elencada se trata da união dos produtores através da associação, como também, o empenho de lideranças na organização, se configura como o diferencial para o bom êxito e resultados positivos.

Através do bom funcionamento da estrutura coletiva, também conseguem apoio e parcerias de outras instituições para exposição e comercialização de seus produtos em feiras, eventos e, ainda conseguem participar de programas de compras governamentais, como os contratos já firmados com a CONAB através do PAA, para o ano de 2017 , no valor de $\mathrm{R} \$ 80.000,00$ (oitenta mil reais), com adicional de $30 \%$ sobre o valor de cada produto da tabela de mercado, por se tratar de produtos orgânicos de acordo com as normas do programa.

Apesar dos problemas mencionados no decorrer desse estudo, pode-se afirmar que o modelo do programa PAIS é essencial para agricultores familiar de baixa renda no estado, seja pela viabilidade econômica e rápido retorno do capital investido em pequena área explorada, seja pela produção de alimentos de boa qualidade, isentos de agrotóxicos, com adoção de práticas sustentável que preservam os bens e serviços ambientais, imprescindíveis à qualidade de vida no planeta. Contudo, muito pode ser feito com os recursos existentes, mas uma transição mais ampla para uma agricultura mais sustentável não ocorrerá sem apoio das instutuições de pesquisa, fomento e assistencia técnica no estado.

Por isso o trabalho foi muito importante para aquisição de vários conhecimento. Especificamente no que tange a agricultura, sabe se que em muitos lugares tidos como subdesenvolvido ou em desenvolvimento a promoção da agricultura familiar, inclusive no ambiente urbano, representa uma alternativa para o suprimento alimentar em muitas cidades e povoados. Além disso, situar o papel da agricultura familiar foi fundamental para entender a relevância da categoria para a manutenção das famílias rurais, bem como nortear os próprios agricultores que residem na Comunidade São Francisco de Assis no Município de Rio Preto da Eva a importância das parcerias governamentais, visto que essa prática garante a sustentabilidade agrícola, econômica e social.

\section{AGRADECIMENTOS}

Ao PPGCMA-ICEN/UFPA, ITEGAM, SEBRAE, Superintendência Federal de Agricultura no Amazonas (SFA-AM) e a Associação da Comunidade São Francisco de Assis, Rio Preto da Eva-AM pelo apoio a pesquisa.

\section{REFERENCIAS}

[1] Santiago, Ocinéia Márcia Andrade. Caracterização da cadeia produtiva de hortaliças em sistema orgânico em Manaus, Amazonas / Ocinéia Márcia Andrade Santiago. 2012.

[2] Guilhoto. Joaquim. J. M et al. A importância do agronegócio familiar no Brasil. RER. Rio de Janeiro volume $44 n^{\circ}$ 03, p 355 , $382 \mathrm{Jul} / \mathrm{Set}(2006)$ 
[3] ANDRADE. Francisco Alcicley Vasconcelos. SOUZA. Paulo Augusto Ramalho de. Empreendedorismo E Desenvolvimento local: Um Estudo Da Agricultura Familiar Na Gleba De Vila Amazônia, No Município de Parintins, Estado Do Amazonas BRASIL.

[4] Dias, R. Mercado Interno de orgânico cresce 40\%. In: Correio do Estado. 2011. Disponível em: http://www.correiodoestado.com.br/noticias/mercado-interno-deorganicos-cresce-40_98034/ Acesso em: 31 de abril de 2011.

[5] Rampazzo, S. E. A questão ambiental no contexto do desenvolvimento econômico. In: BECKER, D. F. (Org.). Desenvolvimento sustentável: necessidade e/ou possibilidade? Santa Cruz do Sul: EDUNISC, 1997.

[6] BRASIL. Lei n. 11.326, de 23 de julho de 2006. Estabelece as diretrizes para a formulação da Política Nacional da Agricultura Familiar e Empreendimentos Familiares Rurais. Diário Oficial. 2006.

[7] Neves, M.F.; Castro, L.T. Projeto integrado de negócios sustentáveis: o conceito. In: Agricultura Integrada Inserindo pequenos produtores de maneira sustentável em modernas cadeias produtivas. São Paulo: atlas 2010. 144p.

[8] PAIVA, T.; PROENÇA, R. Marketing verde. São Paulo: Almedina, 2011. 143p. SEBRAE. Serviço Brasileiro de Apoio às Micro e Pequenas Empresas. Estudos de inteligência de mercados: perfil de mercado. 2010. 17p. (Informe do SEBRAE). Capturado em 12 mai. 2012. Disponível na Internet: http://www.sebrae.com.

[9] Mattei, Lauro. Programa de Aquisição de Alimentos da Agricultura Familiar (PAA): antecedentes, concepção e composição geral do programa. Disponível em:<http://www.inagrof.com.br/revista/index/.

[10] SENAR. Serviço Nacional de Aprendizagem Rural. Brasília. DF. 2003.

[11] CONAB, Companhia Nacional de Abastecimento. PAA Evolução das operações. In: Agricultura e Abastecimento Alimentar: políticas públicas e mercado agrícola. - Brasília: 548p: il. CONAB, 2009.

[12] IBGE. Instituto Brasileiro de Geografia e Estatística. Tábuas completas de mortalidade - 2010.

[13] BRASIL. Lei $n^{\circ} 11.346$, de 15 de setembro de 2006. Cria o Sistema Nacional de Segurança Alimentar e Nutricional. Diário Oficial da União 2006.

[14] Associação dos Agricultores da Comunidade do São Francisco de Assis do Município de Rio Preto da Eva-AM. Relatório Executivo sobre a Associação e Comunidade São Francisco de Assis. (2016).

[15] IDAM. Instituto de Desenvolvimento Agropecuário e Florestal Sustentável do Estado do Amazonas. (2007).
[16] Tomasetto. G. A. Mendras, H. La fin des paysans. Marseille, Actes Sud. 19MOURA, Margarida Maria. Camponeses. $1^{\text {a }} \mathrm{Ed}$ São Paulo: Ática, 2009.

[17] PAIS. Produção Agroecológica Integrada e Sustentável. Mais alimento, trabalho e renda no campo. Saiba como produzir alimentos saudáveis e preservar o meio ambiente. 3. Ed Brasília: SEBRAE, 2009. Disponível em: <http://www.biblioteca.sebrae.com.br/bds/BDS.pdf.

[18] PAIS. Produção Agroecológica Integrada e Sustentável. Mais alimento, trabalho e renda no campo: Saiba como produzir alimentos saudáveis e preservar o meio ambiente. 3. Ed. Brasília: SEBRAE, 2009.

[19] Padovan, M. P. Manual do Agricultor Agroecológico. Dourados-MS: Edição do Autor, 2007.

[20] BRASIL (2009) Ministério da Agricultura, Pecuária e Abastecimento. Legislação para os sistemas orgânicos de produção animal e vegetal. Brasília, MAPA/ACS.

[21] Trento, S.M., Irgang, H.H., Reis, E.M., 2002. Efeito da rotação de culturas, da monocultura e da densidade de plantas na incidência de grãos ardidos em milho. Fitopatologia Brasileira. 27, 609-613.

[22] Associação Brasileira de Normas Técnicas- ABNT. Carvão Vegetal. Análise Imediata. NBR-8112 (MB1857), Outubro 1986.

[23] Wanderley, M. N. B. Agricultura familiar e campesinato: rupturas e continuidades. Estudos Sociedade e Agricultura, Rio de Janeiro, n.21, p. 42-61, out. 2003.

[24] Wanderley M. N B. Morar e trabalhar: o ideal camponês dos assentados de Pitanga: in Travessias. A vivencia da reforma agrária nos assentamentos, Martins $\mathrm{J}$ de $\mathrm{S}$ (coord.), Porto Alegre, UFRGS, Nead. 2003, pp 203-245.

[25] BRASIL. Ministério do Planejamento, Orçamento e Gestão. Secretaria de Planejamento e Investimentos Estratégicos. Plano Plurianual 2008-2011: relatório anual de avaliação - ano base 2009/exercício 2010. Ministério do Desenvolvimento Agrário. Brasília 2011. 